\title{
Comparison of slant open-path flux gradient and static closed chamber techniques to measure soil $\mathrm{N}_{2} \mathrm{O}$ emissions
}

\author{
Mei Bai ${ }^{1}$, Helen Suter ${ }^{1}$, Shu Kee Lam ${ }^{1}$, Thomas K. Flesch ${ }^{2}$, and Deli Chen ${ }^{1}$ \\ ${ }^{1}$ Faculty of Veterinary and Agricultural Sciences, The University of Melbourne, Parkville, Melbourne, VIC 3010, Australia \\ ${ }^{2}$ Department of Earth and Atmospheric Sciences, University of Alberta, Edmonton, AB T6E 2H4, Canada
}

Correspondence: Mei Bai (mei.bai@unimelb.edu.au)

Received: 23 March 2018 - Discussion started: 24 October 2018

Revised: 21 January 2019 - Accepted: 8 February 2019 - Published: 18 February 2019

\begin{abstract}
Improving direct field measurement techniques to quantify gas emissions from cropped agricultural fields is challenging. We compared nitrous oxide $\left(\mathrm{N}_{2} \mathrm{O}\right)$ emissions measured with static closed chambers to those from a newly developed aerodynamic flux gradient (FG) approach. Measurements were made at a vegetable farm following chicken manure application. The FG calculations were made with a single open-path Fourier transform infrared (OP-FTIR) spectrometer (height of $1.45 \mathrm{~m}$ ) deployed in a slant-path configuration, sequentially aimed at retro reflectors at heights of 0.8 and $1.8 \mathrm{~m}$ above ground. Hourly emissions were measured with the FG technique, but once a day between 10:00 and 13:00 with chambers. We compared the concurrent emission ratios (FG/chamber) of these two techniques and found $\mathrm{N}_{2} \mathrm{O}$ emission rates from a celery crop farm measured at midday by FG were statistically higher (1.22-1.40 times) than those from the chambers measured at the same time. Our results suggest the OP-FTIR slant-path FG configuration worked well in this study: it was sufficiently sensitive to detect the $\mathrm{N}_{2} \mathrm{O}$ gradients over our site, giving high temporal resolution $\mathrm{N}_{2} \mathrm{O}$ emissions corresponding to a large measurement footprint.
\end{abstract}

\section{Introduction}

The accurate measurement of soil nitrous oxide $\left(\mathrm{N}_{2} \mathrm{O}\right)$ emissions from agricultural land is challenging. Chambers are commonly used for these measurements (Hutchinson and Mosier, 1981), and chamber-based observations are widely used to calculate greenhouse gas inventories (Dalal et al., 2008). The principle behind the most common type of cham- ber measurement (static, or non-steady state) is to create a sealed control volume over the soil surface, such that by monitoring the gas concentration change during the chamber deployment, one can calculate the surface emission rate (Denmead, 2008). One of the advantages of chambers is that they can be employed at relatively low cost, with simplicity and easy field operation (de Klein et al., 2001). However, chambers have a fundamental limitation - the control volume inevitably perturbs the soil-atmosphere interface (e.g. temperature, pressure), which has the potential to modify the ambient soil emission rate (Denmead, 1979). Moreover, manually operated static chambers are not well-suited to measuring temporal variations in emissions (Denmead et al., 2008; Jones et al., 2011). The temporal variation issue can be addressed by alternative approaches, e.g. a dynamic measurement with automated-chamber opening and closing by pneumatic actuators (Yao et al., 2009) and can be run for many months. However, in many situations the most important disadvantage of chambers is their small surface measurement footprint. With a surface enclosure typically less than $1 \mathrm{~m}^{2}$ and the likelihood that soil emissions vary dramatically at length scales greater than $1 \mathrm{~m}$ (Denmead, 2008; Griffith and Galle, 2000; Turner et al., 2008), many replications are needed to adequately quantify the emissions from an agricultural field (Christensen et al., 1996; Denmead, 1995).

Micrometeorological measurements avoid some of the problems associated with chamber methods (Christensen et al., 1996; Denmead et al., 2010; Li et al., 2008; Pattey et al., 2006). These techniques are based on concentration and wind flow measurements made in the free air above the surface, and they do not perturb the surface environment. They also measure emissions over footprints much larger than those 
from chambers (Hargreaves et al., 1996). The aerodynamic flux gradient (FG) technique is a well-used micrometeorological method in which the vertical flux of gas is inferred from a height gradient in concentration (multiplied by an estimate of the turbulent diffusivity). When measured above a large and homogeneous surface, this atmospheric flux is assumed equal to the underlying surface emission or absorption rate. In this study we used a recently developed modification of the technique. Rather than vertically separated point concentrations, we used a slant-path configuration based on vertically separated long line-averaged measurements (Flesch et al., 2016; Wilson and Flesch, 2016). A single open-path Fourier transform infrared (OP-FTIR) concentration sensor with motorised aiming gives the gas concentrations along the two paths, from which we can calculate the surface emission and deposition rates.

In this study we conducted a set of $\mathrm{N}_{2} \mathrm{O}$ emission measurements from a vegetable farm following manure application. Measurements were made with both static chambers and the slant-path FG approach. Our objectives were to (1) demonstrate the newly developed slant-path FG method at a vegetable farm and (2) compare the emission rates measured by the static chamber and FG techniques.

\section{Materials and methods}

\subsection{Experimental site}

This study was conducted at an intensive vegetable farm in Clyde, Victoria, Australia $\left(38.1^{\circ} \mathrm{S}, 145.3^{\circ} \mathrm{E}\right)$. The site consisted of two adjacent fields of 5.4 (Site 1) and 3.1 ha (Site 2). These sites differ only in the addition of a fertiliser amendment at Site 2 . A celery crop at the 4-5 leaf stage was transplanted to these two sites on 27 February 2014 (Fig. 1). Chicken manure ( $4.3 \% \mathrm{~N}, \mathrm{NH}_{4}^{+}-\mathrm{N}: 4633 \mathrm{mg} \mathrm{kg}^{-1}$, $\mathrm{NO}_{3}-\mathrm{N}: 313 \mathrm{mg} \mathrm{kg}^{-1}$ ) was applied at a rate of $8.2 \mathrm{tha}^{-1}$ at both sites on 28 March. Fertiliser Cal-Gran (a blend of calcium ammonium nitrate and ammonium sulfate, total $23.9 \% \mathrm{~N}$ ) was also applied at both sites at a rate of $200 \mathrm{~kg} \mathrm{ha}^{-1}$ on 15 April. Emission measurements began just prior to manure application and ended on 6 May 2014. The terrain was open and flat with sandy loam topsoils. Prevailing winds were southeast or northwest during this period. The average daily minimum and maximum temperatures were 6 and $33{ }^{\circ} \mathrm{C}$, respectively. The total precipitation (including rainfall and irrigation) during the measurement period was $186 \mathrm{~mm}$.

\subsection{Methodologies}

\subsubsection{Static chamber}

Four static chambers $(50 \times 50 \times 25 \mathrm{~cm})$ were located at each site (Fig. 1). The metal base for each chamber was placed into the soil to a depth of $8 \mathrm{~cm}$ prior to the experiment and re-

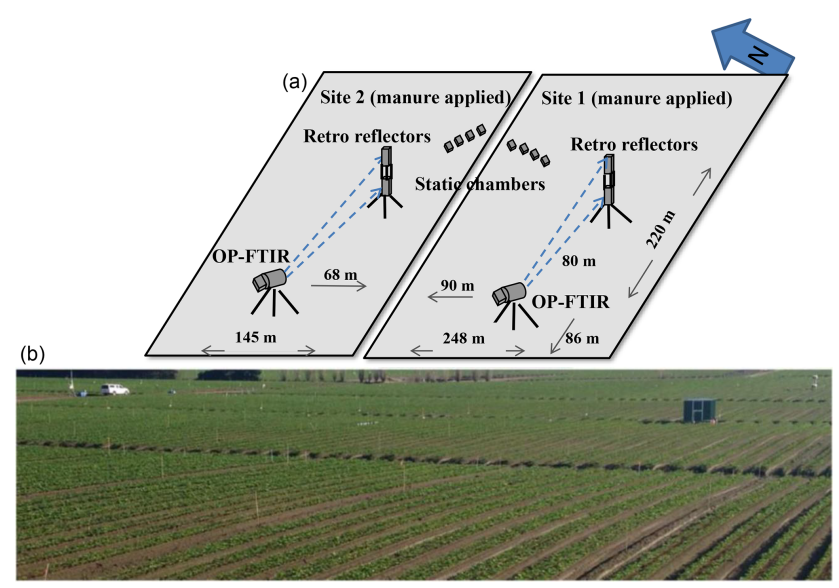

Figure 1. The design of the study (a) and photo of experimental site with OP-FTIR set up (b). Emission measurements were conducted with static chambers (four per site) and FG using the OP-FTIR spectroscopy system with retro reflectors at 0.8 and $1.8 \mathrm{~m}$ above ground. The figure is not to scale.

mained in place through the study. The chamber was made of plexiglass with a built-in ventilation system. Reflective aluminium foil was attached inside the lid to minimise changes in ambient pressure and temperature after the chamber was placed onto the base. A thermocouple Tinytag Transit 2 (TG4080 temperature loggers, West Sussex, UK) was placed on the soil surface inside the chamber to monitor the headspace air temperature. Gas samples $(20 \mathrm{~mL})$ were collected into evacuated $12 \mathrm{~mL}$ vials $\left(\right.$ Exetainer $^{\circledR}$, Labco Ltd., Ceredigion, UK) at 0,30 and $60 \mathrm{~min}$ after chamber placement and analysed at an offsite laboratory by gas chromatography (GC) (Agilent 7890A, Wilmington, USA). The sensitivity of GC for $\mathrm{N}_{2} \mathrm{O}$ concentration was $0.01 \mathrm{ppm}$. Gas samples were collected daily between 10:00 and 13:00 from 29 March to 7 April and on 9, 11 and 16 April. The $\mathrm{N}_{2} \mathrm{O}$ flux was calculated as (Ruser et al., 1998) (Eq. 1):

$Q_{\text {chamber }}=K_{\mathrm{N}_{2} \mathrm{O}}(273 / T)(V / A) \mathrm{d} C / \mathrm{d} t$,

where $Q_{\text {chamber }}$ is the gas flux $\left(\mu \mathrm{g} \mathrm{N}_{2} \mathrm{O}-\mathrm{N} \mathrm{m}^{-2} \mathrm{~h}^{-1}\right) ; K_{\mathrm{N}_{2} \mathrm{O}}$ is $1.25\left(\mu \mathrm{g} \mathrm{N} \mu \mathrm{L}^{-1}\right)$ according to the ideal gas law, where $K_{\mathrm{N}_{2} \mathrm{O}}=P m / R T_{0}$, and $P$ is air pressure (at $1 \mathrm{~atm}$ ), $m$ is molecular mass $\left(28 \mathrm{~g} \mathrm{~mol}^{-1}\right), R$ is gas constant $\left(0.0821 \mathrm{~L} \mathrm{~atm} \mathrm{~K}^{-1} \mathrm{~mol}^{-1}\right)$ and $T_{0}$ is $273 \mathrm{~K}$; $T$ is the air temperature within the chamber $(\mathrm{K}) ; V$ is the total volume of headspace $(\mathrm{L}) ; A$ is a surface area inside the chamber $\left(\mathrm{m}^{2}\right)$; and $\mathrm{d} C / \mathrm{d} t$ is the rate of change in mole fraction of $\mathrm{N}_{2} \mathrm{O}$ in the chamber $\left(\mu \mathrm{LL}^{-1} \mathrm{~h}^{-1}\right)$ determined by linear regression model. The $\mathrm{N}_{2} \mathrm{O}$ mole fraction is provide by $\mathrm{GC}$ in $\mathrm{ppm}$.

\subsubsection{Flux gradient}

The basic principle of the FG method has been welldescribed (Judd et al., 1999; Laubach and Kelliher, 2004; Webb et al., 1980). We followed a modification described in 
Flesch et al. (2016), in which an open-path sensor was used to measure the concentration difference $\left(\Delta C_{\mathrm{L}}\right)$ between two vertically offset slant-paths. The open-path sensor measures gas concentration between the sensor and a distant retro reflector. The concentration difference $\Delta C_{\mathrm{L}}$ is calculated by sequentially aiming the sensor at high and low retro reflectors. Flesch et al. (2016) showed that the conventional FG equation can be transformed into Eqs. (2), (3):

$Q_{\mathrm{FG}}=\left(k_{v} \rho_{\mathrm{a}} u_{*} / S c\right)\left(M_{\mathrm{s}} / M_{\mathrm{a}}\right) \times \kappa \times \Delta C_{\mathrm{L}}$

$\kappa=l_{\mathrm{PATH}} / \int_{x 1}^{x 2}\left[\ln \left(z_{\mathrm{p} 2} / z_{\mathrm{p} 1}\right)-\phi\left(z_{\mathrm{p} 2} / L\right)+\phi\left(z_{\mathrm{p} 1} / L\right)\right] \mathrm{d} x$

where $Q_{\mathrm{FG}}$ is the gas flux $\left(\mathrm{g} \mathrm{m}^{-2} \mathrm{~s}^{-1}\right), k_{v}$ is von Karman's constant $(0.4), \rho_{\mathrm{a}}$ is dry air density $\left(\mathrm{g} \mathrm{m}^{-3}\right), u_{*}$ is friction velocity $\left(\mathrm{m} \mathrm{s}^{-1}\right), S c$ is the turbulent Schmidt number (0.64), $M_{\mathrm{S}}$ and $M_{\mathrm{a}}$ are the molar mass of $\mathrm{N}_{2} \mathrm{O}\left(44 \mathrm{~g} \mathrm{~mol}^{-1}\right)$ and dry air $\left(29 \mathrm{~g} \mathrm{~mol}^{-1}\right), \Delta C_{\mathrm{L}}(\mathrm{ppb})$ is the difference in the line-average volumetric mixing ratio of the gas (relative to dry air) from the lower $\left(z_{\mathrm{p} 1}\right)$ and upper $\left(z_{\mathrm{p} 2}\right)$ paths $(\mathrm{m}$, relative to celery beds surface), $\kappa$ is proportional to the height integral of the gas diffusivity along the FTIR path pair, $l_{\mathrm{PATH}}$ is the sensorretro reflector path length (m, equal for the two paths), and $L$ is atmospheric Obukhov stability length (m). Path heights $\left(z_{\mathrm{p} 1}\right.$ and $\left.z_{\mathrm{p} 2}\right)$ along the path length are given by a fifth-order polynomial fit of height vs. distance from the OP-FTIR spectrometer (path heights were measured in the field at $5 \mathrm{~m}$ intervals). We used the stability correction factor $\phi$ from Flesch et al. (2016).

An estimate of the uncertainty in $Q_{\mathrm{FG}}\left(\delta_{\mathrm{QFG}}\right)$ was calculated as the sum in quadrature of the relative uncertainties in $S c, \Delta C_{\mathrm{L}}$ and $\kappa$ according to the formula described in Flesch et al. (2016). $Q_{\mathrm{FG}}$ values were not calculated when $u_{*}$ $<0.05 \mathrm{~m} \mathrm{~s}^{-1}$.

The FG calculations relied on open-path concentrations measured with a robust Bruker OP-FTIR spectrometer (Matrix-M IRcube, Bruker Optics, Ettlingen, Germany) and two retro reflectors located $80 \mathrm{~m}$ from the spectrometer (PLX Industries, New York, USA). Briefly, the OP-FTIR system measures multiple gas concentrations $\left(\mathrm{N}_{2} \mathrm{O}, \mathrm{CH}_{4}\right.$, $\mathrm{NH}_{3}, \mathrm{CO}_{2}, \mathrm{CO}$ and water vapour) with high precision $\left(\mathrm{N}_{2} \mathrm{O}\right.$ $<0.3 \mathrm{ppb}, \mathrm{CH}_{4}<2 \mathrm{ppb}, \mathrm{NH}_{3}, 0.4 \mathrm{ppb}, \mathrm{CO}_{2}, 1 \mathrm{ppm}, \mathrm{CO}$, $0.1 \mathrm{ppb}$ and water vapour $<5 \%$ ) (Griffith, 1996; Griffith et al., 2008, 2012). More details on the OP-FTIR system can be found in Bai (2010). The spectrometer was mounted at a height of $1.45 \mathrm{~m}$ above ground. A motorised mounting head sequentially aimed the spectrometer to the retro reflectors at 0.8 and $1.8 \mathrm{~m}$ above ground. Line-averaged $\mathrm{N}_{2} \mathrm{O}$ concentrations were measured with an averaging time of $2.5 \mathrm{~min}$. Background $\mathrm{N}_{2} \mathrm{O}$ concentrations were measured prior to manure application in order to assess measurement precision. A sequence of observations were averaged, the standard deviation of the mean was retrieved and the precision of $\mathrm{N}_{2} \mathrm{O}$ concentration measurements (less than $0.3 \mathrm{ppb}$ ) was determined according to Bai (2010). The OP-FTIR measurements were made continuously from 25 March to 16 April, and thereafter measurements were made for 3 days (continuously) per week until 6 May.

A weather station coupled with a three-dimensional sonic anemometer (CSAT3, Campbell Scientific, Logan, UT, USA) was established at a height of $3.0 \mathrm{~m}$ above ground, $50 \mathrm{~m}$ east of Site 2. Fifteen-minute average climatic data including ambient temperature, pressure and wind statistics were recorded by a data logger (CR23X, Campbell Scientific, Logan, UT, USA) at a frequency of $10 \mathrm{~Hz}$. Atmospheric stability parameters of friction velocity $\left(u_{*}\right)$, surface roughness $\left(z_{0}\right)$ and Obukhov stability length $(L)$ were calculated from the ultrasonic anemometer data. We used a data-filtering procedure to remove error-prone observations in the FG calculation according to Flesch et al. (2014).

The FG flux measurements correspond to surface emissions within a flux footprint. The footprint generally extends upwind of the concentration sensors, but its spatial size varies with wind conditions. A concern of this study is that the FG footprint extends beyond our plots and the calculated emission rates are "contaminated" by emissions occurring outside the plot. This possibility was investigated by modelling the FG footprint for our smaller Site 2, where the contamination concerns are greater. The WindTrax dispersion software (http://www.thunderbeachscientific.com, last access: 6 December 2018) was used to simulate the OP-FTIR slant-path set-up, and calculate the fraction of the FG measured flux occurring within the Site 2 plot. We looked at the wind direction that results in a short fetch (NE), and looked at different atmospheric stability conditions and roughness lengths. The results for $z_{0}=0.1 \mathrm{~m}$ (representative of the plot) are shown in Fig. 2. We concluded that during stable night-time conditions the FG emission calculations for Site 2 were maybe contaminated by up to $40 \%$ by outside fluxes. This may result in either over- or underestimation of Site 2 emissions depending on the emission rate outside the plot. In unstable daytime conditions the contamination potential falls to $0 \%-$ $10 \%$. Contamination at Site 1 will not be as serious due to the larger fetches.

The main objective of our study is to compare chamber and FG emission estimates. We looked at periods with concurrent measurements from the two techniques, and hourly flux ratios of $Q_{\mathrm{FG}} / Q_{\text {chamber }}$ measured between 10:00 and 13:00 are compared. Because the comparison took place during the day when conditions were generally unstable, the FG contamination potential is low (and will be ignored). The contamination potential does highlight a concern with micrometeorological measurements, that a large measurement footprint may extend outside the study area and result in measurement errors. 


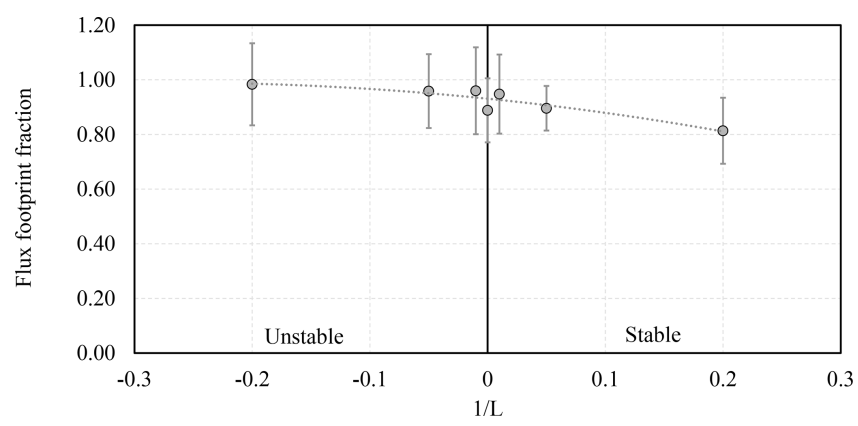

Figure 2. Estimated flux footprint fraction at Site 2 plotted versus atmospheric stability (the reciprocal of the Obukhov length $L$ ). The model results are for a roughness length $z_{0}=0.1 \mathrm{~m}$.

\section{Results and discussion}

\subsection{Daily $\mathrm{N}_{2} \mathrm{O}$ flux}

The FG measurements gave high temporal resolution of fluxes and this provides an opportunity to study the pattern of $\mathrm{N}_{2} \mathrm{O}$ emissions in detail. Here we only describe the temporal flux measurements from Site 1.

\subsubsection{The flux gradient fluxes}

Hourly $\mathrm{N}_{2} \mathrm{O}$ fluxes showed large temporal variation during the experimental period in response to fertilisation. There was a rapid increase in $\mathrm{N}_{2} \mathrm{O}$ emission from a background level of $0.6 \mathrm{mg} \mathrm{N} \mathrm{N}_{2} \mathrm{O}-\mathrm{N} \mathrm{m}^{-2} \mathrm{~h}^{-1}$ before manure application to a peak of $158.0 \mathrm{mg} \mathrm{N}_{2} \mathrm{O}-\mathrm{N} \mathrm{m}^{-2} \mathrm{~h}^{-1}$ within $24 \mathrm{~h}$ after application, which could be attributed to both nitrification and denitrification. After the peak, several spikes between 16 and 17 April were also observed associated with fertiliser application, followed by a decline in emissions to an average of $2.5 \mathrm{mg} \mathrm{N}_{2} \mathrm{O}-\mathrm{N} \mathrm{m}^{-2} \mathrm{~h}^{-1}$ (Fig. 3a). One of the conclusions we draw from Fig. $3 b$ is that the slant-path FG system is sensitive enough to measure the $\mathrm{N}_{2} \mathrm{O}$ fluxes that accompanied fertilisation at our site; i.e. the measurement uncertainty as represented by $1 \sigma$ is generally well below the flux magnitude.

In addition to the long-term pattern of decreasing emissions after manure application, we observed a diurnal pattern where maximum emissions tended to occur in the late afternoon (16:00) (Fig. 3b). We believe this is related to the time of maximum soil surface temperature, which occurs after the peak air temperature (Christensen et al., 1996; Wang et al., 2013). A strong diurnal emission pattern implies that once-a-day snapshot emission measurements (e.g. chambers) would almost certainly give a biased estimate of the daily average emission rate. We also noticed occasional high emissions at night, which were closely related to precipitation events. Negative $\mathrm{N}_{2} \mathrm{O}$ fluxes calculated from the FG measurements most likely represent instrument noise, as the flux magnitudes were below the detectable limit of our OP-FTIR system; i.e. the uncertainty represented by the $1 \sigma$ error bars in Fig. 3 span zero.

\subsubsection{Chamber fluxes}

Nitrous oxide fluxes from the static chambers (once-a-day snapshots) were in general agreement with the FG measurements in terms of the long-term background exchange patterns (Fig. 3): hourly fluxes rose from a background level of $1.12 \mathrm{mg} \mathrm{N}_{2} \mathrm{O}-\mathrm{N} \mathrm{m}^{-2} \mathrm{~h}^{-1}$ (before manure application; data are not shown), reached a spike of $3.48 \mathrm{mg} \mathrm{N}_{2} \mathrm{O}-\mathrm{N} \mathrm{m}^{-2} \mathrm{~h}^{-1}$ $48 \mathrm{~h}$ after manure application, then dropped to a minimum of $1.02 \mathrm{mg} \mathrm{N}_{2} \mathrm{O}-\mathrm{N} \mathrm{m}^{-2} \mathrm{~h}^{-1}$ on 5 April. A maximum emission peak of $3.55 \mathrm{mg} \mathrm{N}_{2} \mathrm{O}-\mathrm{N} \mathrm{m}^{-2} \mathrm{~h}^{-1}$ was measured on 16 April and was most likely related to fertiliser application.

\subsection{Comparison of the two measurement techniques}

We selected the concurrent measurements from FG and the chambers and a total of 23 comparison pairs were obtained during the study period (note that each chamber observation is an average from four replicate chambers). We calculated the ratio $Q_{\mathrm{FG}} / Q_{\text {chamber }}$ of these concurrent pairs.

The $Q_{\mathrm{FG}} / Q_{\text {chamber }}$ ratio showed large variation, with values ranging between 0.4 and 4.9. The $Q_{\mathrm{FG}} / Q_{\text {chamber }}$ data follow a non-normal distribution. To better interpret these data we log-transformed the ratios (Abdi et al., 2015). The average of the natural logarithm of the ratio, converted back to the ratio units, gives the geometric mean (the process was duplicated to calculate the confidence interval $\alpha=0.9$ ). The geometric mean of $Q_{\mathrm{FG}} / Q_{\text {chamber }}$ was 1.40 , with a confidence interval ranging from 1.15 to 1.69 . This means that on average the FG measured fluxes were $40 \%$ higher than those from the chambers, and this difference was statistically significant.

Differences between chamber and micrometeorological measurements have been previously noted. Some studies have reported that micrometeorological techniques gave emission rates that were $50 \%-60 \%$ of those from chambers (Christensen et al., 1996; Neftel et al., 2010). In contrast, Wang et al. (2013) reported that $\mathrm{N}_{2} \mathrm{O}$ emissions measured in the chambers were $17 \%-20 \%$ lower than from the eddy covariance micrometeorological technique, and Norman et al. (1997) reported that chamber measurements were $30 \%$ lower than micrometeorological measurements. Sommer et al. (2004) found that static vented chambers underestimated $\mathrm{N}_{2} \mathrm{O}$ emissions from manure piles by $12 \%-22 \%$ compared to mass balance measurements.

Discrepancies between FG and chamber fluxes could be due to very different measurement footprints. Large spatial variability is a characteristic of soil $\mathrm{N}_{2} \mathrm{O}$ emissions. For example, Turner et al. (2008) reported that $\mathrm{N}_{2} \mathrm{O}$ emissions varied from 30 to $800 \mathrm{ng} \mathrm{N}_{2} \mathrm{O}-\mathrm{N} \mathrm{m}^{-2} \mathrm{~s}^{-1}$ over an irrigated dairy pasture $\left(8100 \mathrm{~m}^{2}\right)$. This high variability, together with the substantial difference in measurement footprint size (cham- 

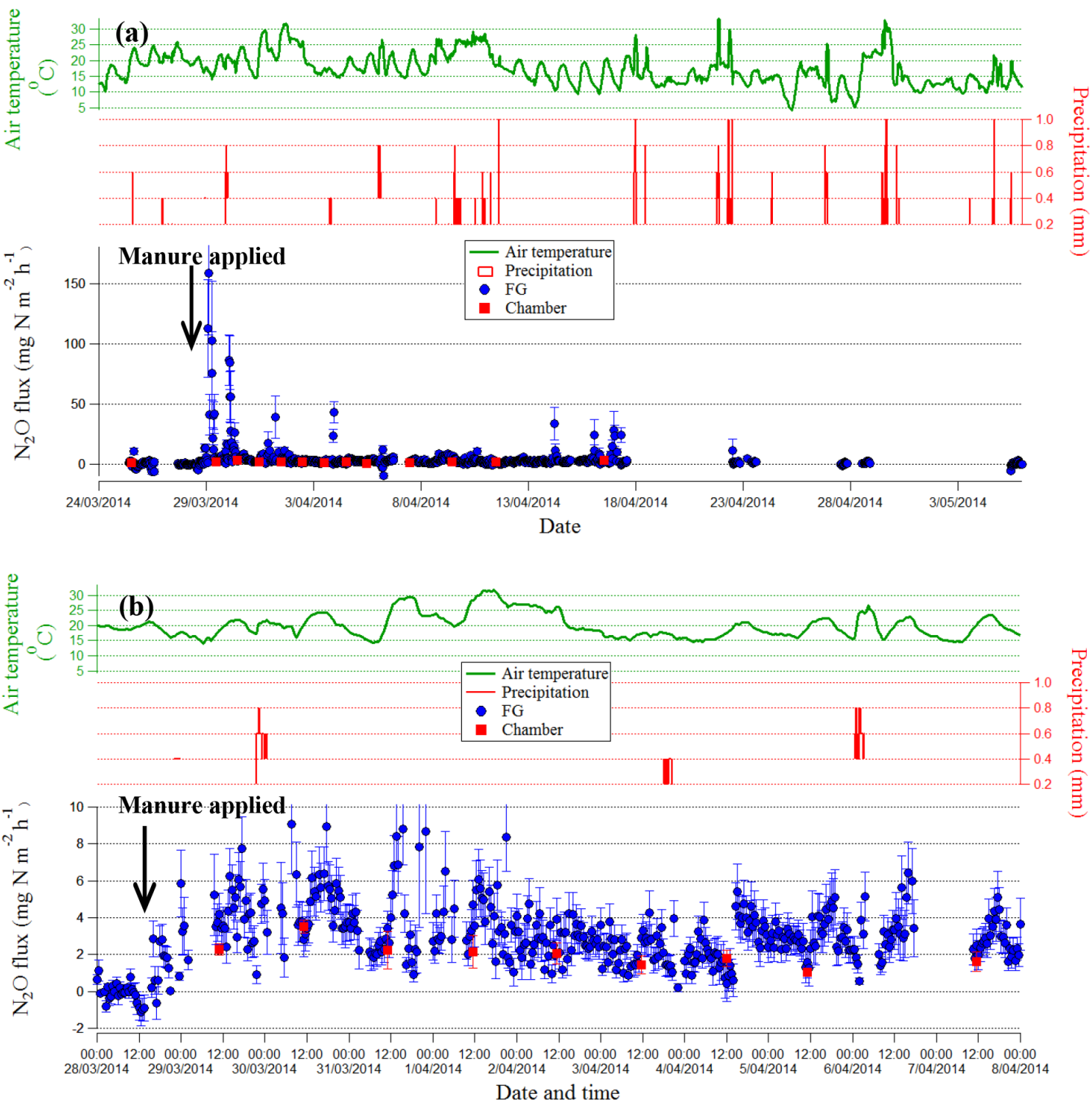

Figure 3. (a) Hourly $\mathrm{N}_{2} \mathrm{O}$ fluxes measured by FG and static chambers from 25 March to 6 May. Air temperature and precipitation are plotted during the same period. (b) Subset of $\mathrm{N}_{2} \mathrm{O}$ fluxes from 28 March to 8 April. Error bars (both upper and lower panels) represent $1 \sigma$ estimate of measurement uncertainty $\left(\delta_{\mathrm{QFG}}\right)$ for the FG measurements and standard error for chambers. Manure was applied on 28 March 2014.

bers $<1 \mathrm{~m}^{2}$ vs $\mathrm{FG}>1000 \mathrm{~m}^{2}$ ), will likely result in differences between the two techniques because the chambers are not capable of accounting for this variability, unless many chambers are used, while the FG method can. If this explains the difference between the two techniques, then discrepancies between chambers and micrometeorological techniques should be site dependent, i.e. dependent on the degree of spatial variability in emissions at each site.

Several researchers have reported that chamber flux calculation procedures introduced large uncertainty in $\mathrm{N}_{2} \mathrm{O}$ emissions (Levy et al., 2011; Venterea et al., 2010). In particular, using linear regression to determine the rate of change $\mathrm{d} C / \mathrm{d} t$ in Eq. (1) can lead to an underestimate of emis- sions (Anthony et al., 1995; Matthias et al., 1978). Venterea (2013) concluded that the typical calculations used for non-steady-state chambers underestimated $\mathrm{N}_{2} \mathrm{O}$ emissions by $20 \%-50 \%$. To examine the potential bias in $\mathrm{N}_{2} \mathrm{O}$ emissions when $\mathrm{d} C / \mathrm{d} t$ is estimated with a linear regression model, we also calculated the results using a non-linear monomolecular model (Bolker, 2007). The monomolecular model is one of the simplest saturating functions and follows (Eq. 4):

$C_{\mathrm{N}_{2} \mathrm{O}}=a_{0}+a_{1}\left(1-\exp \left(-a_{2} / a_{1} \times t\right)\right)$,

where $C_{\mathrm{N}_{2} \mathrm{O}}$ is the mole fraction of $\mathrm{N}_{2} \mathrm{O}, a_{0}$ is the intercept corresponding to the $\mathrm{N}_{2} \mathrm{O}$ mole fraction at time $t=0, a_{1}$ is 
the horizontal asymptote at $t=+\infty, a_{2}$ is the slope $(\mathrm{d} C / \mathrm{d} t)$ at $t=0$, and $t$ is time after chamber placement (h).

Chamber fluxes calculated using the non-linear $\mathrm{d} C / \mathrm{d} t$ ( $\left.Q_{\text {chamber-non-linear }}\right)$ were 1.15 times higher than $Q_{\text {chamber }}$ estimated using linear regression. Comparing the concurrent fluxes of $Q_{\mathrm{FG}}$ and $Q_{\text {chamber-non-linear, we found the geomet- }}$ ric mean of $Q_{\mathrm{FG}} / Q_{\text {chamber-non-linear }}$ to be 1.22 (confidence interval of 0.99 to 1.49 ). Using 10000 bootstrap resamples (Efron and Tibshirani, 1994), we computed 10000 potential mean fluxes from the non-linear model, 9540 of which were greater than 1, and 460 were lower than 1 . This result suggests the use of the non-linear $\mathrm{d} C / \mathrm{d} t$ calculation has resulted in better agreement with the FG estimates.

While there is a long and successful history of FG applications, there are still questions about its implementation. The value of the turbulent Schmidt number $(S c)$ in Eq. (2) is debated (Flesch et al., 2002). There are also concerns regarding the accuracy of FG during light winds. In our study the light wind data $\left(0.05-0.15 \mathrm{~m} \mathrm{~s}^{-1}\right)$ accounted for $24 \%$ of the measurement periods. We found the FG uncertainty $\left(\delta_{\mathrm{QFG}} / Q_{\mathrm{FG}}\right)$ increased from 0.41 to 1.25 when the friction velocity $\left(u_{*}\right)$ dropped from 0.15 to $0.05 \mathrm{~m} \mathrm{~s}^{-1}$. However, we note that in this study the periods in which we compared FG and chamber measurements were not light wind periods.

Using the FG method, we estimated that the cumulative $\mathrm{N}_{2} \mathrm{O}$ emissions over the 41-day observation period were $14.6 \mathrm{~kg} \mathrm{~N} \mathrm{ha}^{-1}$, corresponding to $3.7 \%$ of total applied $\mathrm{N}$.

\section{Conclusions}

Our results showed that soil $\mathrm{N}_{2} \mathrm{O}$ emissions measured by FG and static chambers (linear $\mathrm{d} C / \mathrm{d} t$ ) were statistically different, with fluxes from FG being on average $40 \%$ higher. Using a non-linear calculation of $\mathrm{d} C / \mathrm{d} t$ in the chambers decreased the disagreement to $22 \%$. Given the likelihood of large spatial variability in $\mathrm{N}_{2} \mathrm{O}$ emissions, and the vastly different measurement footprints of the two methods, it is not surprising the two techniques give different results. It is difficult to conclude that one technique or the other is biased based on this experiment alone. However, the relationship we observed, together with other reports on the biases created by chamber calculation procedures, supports an interpretation that our FG emission calculations were accurate and in this instance the chamber measurements were biased too low.

The OP-FTIR flux gradient system used here showed the capability for real-time emission measurements over a large spatial footprint with no surface interference. Furthermore, being free from pumps and tubing, the open-path FG system would be particularly advantageous for measuring multiple gas emissions, including "sticky" gases like $\mathrm{NH}_{3}$.
Data availability. The raw data are not available to the public. For any inquiry about the data, please contact the corresponding author (mei.bai@unimelb.edu.au).

Author contributions. DC, HS, SKL, MB and TF designed the experiments and MB and SKL carried them out. TF and MB developed the techniques. MB prepared the manuscript with contributions from all co-authors.

Competing interests. The authors declare that they have no conflict of interest.

Acknowledgements. This study was funded by the Australian Department of Agriculture (DA), and the Canadian Agricultural Greenhouse Gases Program (AGGP). The authors thank Schruers' vegetable farm, Adam Schruers and staff for their great support. The authors also thank Rohan Davies from BASF Australia Ltd. for providing assistance. We gratefully acknowledge the assistance of the staff and students from the Faculty of Veterinary and Agricultural Sciences soil research group at the University of Melbourne during this campaign. We especially thank Raphaël Trouvé for helping with the non-linear model analysis. The valuable comments from all reviewers were appreciated.

Edited by: Christian Brümmer

Reviewed by: Chris Flechard and two anonymous referees

\section{References}

Abdi, D., Cade-Menun, B. J., Ziadi, N., and Parent, L.-É.: Compositional statistical analysis of soil ${ }^{31} \mathrm{P}-\mathrm{NMR}$ forms, Geoderma, 257-258, 40-47, 2015.

Anthony, W. H., Hutchinson, G. L., and Livingston, G. P.: Chamber measurement of soil-atmosphere gas exchange: Linear vs. diffusion-based flux models, Soil Sci. Soc. Am. J., 59, 1308 1310, 1995.

Bai, M.: Methane emissions from livestock measured by novel spectroscopic techniques, School of Chemistry, University of Wollongong, p. 303, 2010.

Bolker, B.: Ecological Models and Data in R, Princeton University Press, The United States of America, 2007.

Christensen, S., Ambus, P., Arah, J. R. M., Clayton, H., Galle, B., Griffith, D. W. T., Hargreaves, K. J., Klemedtsson, L., Lind, A. M., Maag, M., Scott, A., Skiba, U., Smith, K. A., Welling, M., and Wienhold, F. G.: Nitrous oxide emission from an agricultural field: comparison between measurements by flux chamber and micrometerological techniques, Atmos. Environ., 30, 41834190, 1996.

Dalal, R. C., Allen, D. E., Livesley, S. J., and Richards, G.: Magnitude and biophysical regulators of methane emission and consumption in the Australian agricultural, forest, and submerged landscapes: a review, Plant Soil, 309, 43-76, 2008.

de Klein, C. A. M., Sherlock, R. R., Cameron, K. C., and van der Weerden, T. J.: Nitrous oxide emissions from agricultural soils 
in New Zealand - A review of current knowledge and directions for future research, J. Roy. Soc. New Zeal., 31, 543-574, 2001.

Denmead, O. T.: Chamber systems for measuring nitrous oxide emission from soils in the field, Soil Sci. Soc. Am. J., 43, 8995, 1979.

Denmead, O. T.: Novel meteorological methods for measuing trace gas fluxes, Philos. T. R. Soc. A., 351, 383-396, 1995.

Denmead, O. T.: Approaches to measuring fluxes of methane and nitrous oxide between landscapes and the atmosphere, Plant Soil, 309, 5-24, 2008.

Denmead, O. T., Chen, D., Griffith, D. W. T., Loh, Z. M., Bai, M., and Naylor, T.: Emissions of the indirect greenhouse gases $\mathrm{NH}_{3}$ and $\mathrm{NO}_{x}$ from Australian beef cattle feedlots, Aust. J. Exp. Agr., 48, 213-218, 2008.

Denmead, O. T., Macdonald, B. C. T., Bryant, G., Naylor, T., Wilson, S., Griffith, D. W. T., Wang, W. J., Salter, B., White, I., and Moody, P. W.: Emissions of methane and nitrous oxide from Australian sugarcane soils, Agr. Forest Meteorol., 150, 748-756, 2010

Efron, B. and Tibshirani, R. J.: An intruduction to bookstrap, Chapman\&Hall/CRC, Boca Raton, London, New York, Washington, D.C., 1994.

Flesch, K. T., Baron, V., Wilson, J., Griffith, D. W. T., Basarab, J., and Carlson, P.: Agricultural gas emissions during the spring thaw: Applying a new measuremnt technique, Agr. Forest Meteorol., 221, 111-121, 2016.

Flesch, T. K., Prueger, J. H., and Hatfield, J. L.: Turbulent Schmidt number from a tracer experiment, J. Appl. Meteorol., 111, 299307, 2002

Flesch, T. K., McGinn, S. M., Chen, D. L., Wilson, J. D., and Desjardins, R. L.: Data filtering for inverse dispersion emission calculations, Agr. Forest Meteorol., 198-199, 1-6, 2014.

Griffith, D. W. T.: Synthetic calibration and quantitative analysis of gas-phase FT-IR spectra, Appl. Spectrosc., 50, 59-70, 1996.

Griffith, D. W. T. and Galle, B.: Flux measurements of $\mathrm{NH}_{3}, \mathrm{~N}_{2} \mathrm{O}$ and $\mathrm{CO}_{2}$ using dual beam FTIR spectroscopy and the flux gradient technique, Atmos. Environ., 34, 1087-1098, 2000.

Griffith, D. W. T., Bryant, G. R., Hsu, D., and Reisinger, A. R.: Methane emissions from free-ranging cattle: comparison of tracer and integrated horizontal flux techniques, J. Environ. Qual., 37, 582-591, 2008.

Griffith, D. W. T., Deutscher, N. M., Caldow, C., Kettlewell, G., Riggenbach, M., and Hammer, S.: A Fourier transform infrared trace gas and isotope analyser for atmospheric applications, Atmos. Meas. Tech., 5, 2481-2498, https://doi.org/10.5194/amt-52481-2012, 2012.

Hargreaves, K. J., Wienhold, F. G., Klemedtsson, L., Arah, J. R. M., Beverland, I. J., Fowler, D., Galle, B., Griffith, D. W. T., Skiba, U., Smith, K. A., Welling, M., and Harrris, G. W.: Measurement of nitrous oxide from Agricultural land using micrometeorological methods, Atmos. Environ., 30, 1563-1571, 1996.

Hutchinson, G. L. and Mosier, A. R.: Improved soil cover method for field measurement of nitrous oxide fluxes, Soil Sci. Soc. Am. J., 45, 311-316, 1981.

Jones, S. K., Famulari, D., Di Marco, C. F., Nemitz, E., Skiba, U. M., Rees, R. M., and Sutton, M. A.: Nitrous oxide emissions from managed grassland: a comparison of eddy covariance and static chamber measurements, Atmos. Meas. Tech., 4, 2179_ 2194, https://doi.org/10.5194/amt-4-2179-2011, 2011.
Judd, M. J., Kellier, F. M., Ulyatt, M. J., Lassey, K. R., Tate, K. R., Shelton, D., Harvey, M. J., and Walker, C. F.: Net methane emissions from grazing sheep, Glob. Change Biol., 5, 647-657, 1999.

Laubach, J. and Kelliher, F. M.: Measuring methane emission rates of a dairy cow herd by two micrometeorological techniques, Agr. Forest Meteorol., 125, 279-303, 2004.

Levy, P. E., Gray, A., Leeson, S. R., Gaiawyn, J., Kelly, M. P. C., Cooper, M. D. A., Dinsmore, K. J., Jones, S. K., and Sheppard, L. J.: Quantification of uncertainty in trace gas fluxes measured by the static chamber method, Eur. J. Soil Sci., 62, 811-821, 2011.

Li, J., Tong, X., Yu, Q., Dong, Y., and Peng, C.: Micrometeorological measurements of nitrous oxide exchange above a cropland, Atmos. Environ., 42, 6992-7001, 2008.

Matthias, A. D., Yarger, D. N., and Weinback, R. S.: A numerical evaluation of chamber methods for determining gas fluxes, Geophys. Res. Lett., 5, 765-768, 1978.

Neftel, A., Ammanna, C., Fischer, C., Spirig, C., Conen, F., Emmenegger, L., Tuzson, B., and Wahlen, S.: $\mathrm{N}_{2} \mathrm{O}$ exchange over managed grassland: Application of a quantum cascade laser spectrometer for micrometeorological flux measurements, Agr. Forest Meteorol., 150, 775-785, 2010.

Norman, J. M., Kucharik, C. J., Gower, S. T., Baldocchi, D. D., Crill, P. M., Rayment, M., Savage, K., and Striegl, R. G.: A comparison of six methods for measuring soil-surface carbon dioxide fluxes, J. Geophys. Res., 102, 28771-28777, 1997.

Pattey, E., Strachan, I. B., Desjardins, R. L., Edwards, G. C., Dow, D., and MacPherson, J. I.: Application of a tunable diode laser to the measurement of $\mathrm{CH}_{4}$ and $\mathrm{N}_{2} \mathrm{O}$ fluxes from field to landscape scale using several micrometeorological techniques, Agr. Forest Meteorol., 136, 222-236, 2006.

Ruser, R., Flessa, H., Schilling, R., Steindl, H., and Beese, F.: Soil compaction and fertilization effects on nitrous oxide and methane fluxes in potato fields, Soil Sci. Soc. Am. J., 62, 15871595, 1998.

Sommer, S. G., McGinn, S. M., Hao, X., and Larney, F. J.: Techniques for measuring gas emissions from a composting stock pile of cattle manure, Atmos. Environ., 38, 4643-4652, 2004.

Turner, D. A., Chen, D., Galbally, I. E., Leuning, R., Edis, R. B., Li, Y., Kelly, K., and Phillips, F.: Spatial variability of nitrous oxide emissions from an Australian irrigated dairy pasture, Plant Soil, 309, 77-88, 2008.

Venterea, R. T.: Theoretical comparison of advanced methods for calculating nitrous oxide fluxes using non-steady state chambers, Soil Sci. Soc. Am. J., 77, 709-720, 2013.

Venterea, R. T., Dolan, M., and Ochsner, T. E.: Urea decreases nitrous oxide emissions compared with anhydrous ammonia in a Minnesota corn cropping system, Soil Sci. Soc. Am. J., 74, 407418, 2010.

Wang, K., Zheng, X., Pihlatie, M., Vesala, T., Liu, C., Haapanala, S., Mammarella, I., Rannik, Ü., and Liu, H.: Comparison between static chamber and tunable diode laser-based eddy covariance techniques for measuring nitrous oxide fluxes from a cotton field, Agr. Forest Meteorol., 171-172, 9-19, 2013.

Webb, E. K., Pearman, G. I., and Leuning, R.: Correction of flux measurements for chemistry effects due to heat and water vapour transfer, Q. J. Roy. Meteor. Soc., 106, 85-100, 1980. 
Wilson, J. D. and Flesch, T. K.: Generalized flux-gradient technique pairing line-average concentrations on vertically separated paths, Agr. Forest Meteorol., 220, 170-176, 2016.
Yao, Z., Zheng, X., Xie, B., Liu, C., Mei, B., Dong, H., ButterbachBahl, K., and Zhu, J.: Comparison of manual and automated chambers for field measurements of $\mathrm{N}_{2} \mathrm{O}, \mathrm{CH}_{4}, \mathrm{CO}_{2}$ fluxes from cultivated land, Atmos. Environ., 43, 1888-1896, 2009. 